\title{
PENGARUH REVOLUSI INDUSTRI 4.0 TERHADAP WAJAH PERPUSTAKAAN PERGURUAN TINGGI
}

\author{
Prasetyo Adi Nugroho \\ Perpustakaan Universitas Airlangga \\ e-mail: prasetyo.adi@staf.unair.ac.id
}

\begin{abstract}
ABSTRAK
Indonesia telah masuk pada revolusi industri 4.0 dimana hampir segala aspek kehidupan berhubungan dengan dunia digital. Salah satu aspek yang mengalami perubahan signifikan yaitu pada sektor pendidikan. Perpustakaan sebagai penyedia informasi dan koleksi literatur juga ikut berubah. Salah satu perubahan yaitu penggunaan teknologi digital dalam koleksinya melalui penyediaan koleksi e-book dan e-journal. Berbicara mengenai perpustakaan, tidak hanya membahas masalah koleksi pustaka yang dimiliki, masih ada pustakawan yang dapat menjadi nilai jual dan penguat keberadaan perpustakaan. Melalui revolusi industri 4.0 maka peran perpustakaan perguruan tinggi telah bergeser sebagai tempat untuk mencari bantuan dalam proses mengubah informasi menjadi pengetahuan baru sehingga terjadi mobilisasi pengetahuan. Kehadiran Revolusi industri 4.0 telah merubah wajah dari perpustakaan perguruan tinggi terutama terhadap pekerjaan yang bersifat teknis.
\end{abstract}

Kata Kunci: Revolusi Industri, Perpustakaan, Pustakawan

\section{PENDAHULUAN}

Revolusi industri 4.0 menyebabkan internet dan web di seluruh dunia mengalami pertumbuhan yang sangat masif. Bahkan setiap beberapa menit selalu ada konten baru yang dikembangkan, sehingga semakin banyak pengguna berusaha mengakses Internet. Internet memungkinkan lebih banyak orang mendapatkan akses ke informasi lebih cepat daripada sebelumnya. Hampir setiap orang mencari wawasan, mengembangkan penelitian, dan hiburan yang luar biasa luasnya dari Internet. Masyarakat yang serba ingin tahu dapat menjelajahi hal hal baru yang tidak mungkin dilakukan di era sebelumnya dengan metode baru pula dengan internet (Moje, 2015). Demikian pula para pelaku usaha dapat mengevaluasi tren bisnis yang ada dengan mendapatkan informasi tentang pesaing dan produk mereka agar dapat memperluas lingkup usaha mereka. oleh sebab itu banyak instansi serta tempat publik menyediakan akses internet untuk mencakupi kebutuhan masyarakat era digital (Alvermann and Sanders, 2019).

Indonesia telah masuk pada revolusi industri 4.0 dimana hampir segala aspek kehidupan berhubungan dengan dunia digital. Revolusi ini ditandai dengan hilangnya pembatas antara jarak dan waktu masyarakat didunia melalui jaringan digital untuk terus terkoneksi satu sama lain. Manusia bisa menembus batas jarak karena ketersediaan modal transportasi yang cepat dan terjangkau serta bisa berkomunikasi dengan satu sama lain tanpa hambatan waktu merupakan hal utama dalam era ini. Dunia menjadi lebih terbuka dan hal apapun yang dilakukan oleh suatu masyarakat bisa diketahui oleh masyarakat lain dalam waktu singkat (Suwono, 2017).

Teknologi baru menciptakan peluang belajar yang menantang praktik tradisional sekolah dan perguruan tinggi. siklus kegiatan belajar mengajar ini memungkinkan orang dari segala usia menuntut ilmu dengan persyaratan mereka sendiri. Orang-orang di seluruh dunia mengambil pendidikan mereka dari sekolah dan ke rumah, perpustakaan, kafe internet dan tempat kerja, di mana mereka dapat memutuskan apa yang ingin mereka pelajari, kapan mereka ingin belajar dan bagaimana mereka ingin belajar (Bauer and Ahooei, 2018).

Saat ini, peran perpustakaan perguruan tinggi telah mengalami perubahan dengan mengikuti tren perkembangan global, tuntutan teknologi, dan kebutuhan pemustaka yang dilayaninya. Perubahan wajah perpustakaan perpustakaan perguruan tinggi ke depan 
dengan berbasis digital adalah suatu keharusan yang dipenuhi perpustakaan perguruan tinggi.

Wajah perpustakaan konvensional sebagai tempat untuk peminjaman dan pengembalian buku harus dirubah dari pemikiran seorang pustakawan dan semua stakeholders yang terlibat dalam pengembangan perpustakaan. Hal ini sebagai tantangan perpustakaan perguruan tinggi sebagai akibat adanya revolusi industri 4.0 yang menimbulkan ketidaknyamanan bagi semua pihak.

Dalam kasusnya untuk perpustakaan di Indonesia masih memiliki banyak kekurangan yang dimana permasalahannya sendiri datang dari intra perpustakaan tersebut, seperti Sumber Daya Manusia yang tidak memadai baik itu dalam status jumlah dan intelektual, anggaran yang tidak mendukung, ketidaksiapan perpustakaan dalam merubah kebiasaan lama yang sudah melekat, pemustaka yang masih berfikiran konvensional dan ketidakinginan berkembangnya suatu perpustakaan karena merasa masih sanggup melakukan pelayanan terbaik di versi perpustakaannya saat ini. Permasalahan utamanya dikarenakan ketidakbiasaan masyarakat di Indonesia bekerja dengan mesin robot yang seperti dilakukan di industri 4.0 (Nora, 2018).

Pembuatan tulisan ini bertujuan untuk melihat wajah perpustakaan perguruan tinggi dalam menghadapi revolusi industri 4.0 yang sedang marak-maraknya di deklarisasikan di Indonesia dan juga peran seorang pustakawan dalam menyikapi revolusi industri 4.0

\section{KAJIAN PUSTAKA}

\section{Revolusi Industri 4.0}

Menurut Klaus Schwab, Founder dan Executive Chairman of the World Economic Forum dalam bukunya 'The Fourth Industrial Revolution' (2016), revolusi industri generasi keempat ini ditandai dengan kemunculan superkomputer, robot pintar, kendaraan tanpa pengemudi, editing genetik dan perkembangan neuroteknologi yang memungkinkan manusia untuk lebih mengoptimalkan fungsi otak. Pada era ini ditemukan pola baru ketika disruptif teknologi (disruptive technology) hadir begitu cepat dan mengancam keberadaan perusahaanperusahaan incumbent. Revolusi Industri 4.0 menerapkan konsep otomatisasi yang dilakukan oleh mesin tanpa memerlukan tenaga manusia dalam penerapannya, di mana hal tersebut merupakan hal vital yang dibutuhkan oleh para pelaku industri demi efisiensi waktu, tenaga kerja, dan biaya.

\section{Perpustakaan Perguruan Tinggi}

Perpustakaan Perguruan Tinggi adalah perpustakaan yang merupakan bagian integral dari kegiatan pendidikan, penelitian dan pengabdian pada masyarakat dan berfungsi sebagai pusat sumber belajar untuk mendukung tercapainya tujuan pendidikan yang berkedudukan di perguruan tinggi (PP RI Nomor 24 Tahun 2014 Pasal 1 angka 10).

Keberadaan sebuah perpustakaan perguruan tinggi begitu penting sebagai unsur penunjang dalam proses pembelajaran, penelitian dan pengabdian pada masyarakat sehingga perpustakaan perguruan tinggi diibaratkan sebagai jantungnya universitas. Dengan kata lain bahwa perpustakaan merupakan suatu organ vital yang harus dimiliki oleh lembaga pendidikan. Tanpa adanya perpustakaan maka suatu lembaga pendidikan akan statis (mati).

\section{Pustakawan sebagai Blended Librarian}

Pemahaman pustakawan sebagai "Blended Librarian" diperkenalkan oleh Steven Bell dan John Shark tahun 2004 dengan pengertian bahwa pustakawan perguruan tinggi perlu menggabungkan keterampilan tradisional dengan keterampilannya memanfaatkan baik hardware maupun software, serta kemampuannya sebagai instruktur pelatihan literasi informasi agar sivitas akademik mampu memanfaatkan fasilitas perpustakaan berbasis teknologi komputer dengan tepat untuk membantu proses belajar-mengajar mereka. Menurut Bell dan Shark,konsep "blended librarian" lahir karena perlawanan pustakawan sebagai profesi yang termarginalkan di lingkungan perguruan tinggi.

"Blended Librarian" merupakan pilihan terbaik bagi pustakawan dengan menggabungkan keterampilan dan nilai-nilai tradisional dengan perkembangan terbaru di bidang teknologi informasi dan komunikasi dan mengembangkan desain instruksional dalam rangka memenuhi kebutuhan peserta didik abad ke-21.

Di lembaga pendidikan, pustakawan adalah salah satu kelompok profesi yang memiliki andil dalam memastikan tercapainya tujuan pendidikan. Khusus di perguruan tinggi, peran pustakawan ini sangat strategis, dimana kebutuhan literatur yang mendukung pelaksanaan kurikulum sangat tergantung pada pustakawan (Naibaho, 2017)

\section{Metodologi}

Artikel ini ditulis oleh penulis berdasarkan teori yang ditemukan dari beberapa literatur, pengamatan, 
dan pengumpulan data-data yang diperoleh dari sumber primer dan sekunder serta berbagai tulisan mengenai revolusi industri 4.0. Menurut Sugiyono (2010, hal. 147) analisis deskriptif adalah menganalisis data dengan cara mendeskripsikan atau menggambarkan data yang telah terkumpul sebagaimana adanya tanpa bermaksud untuk membuat kesimpulan yang berlaku umum atau generalisasi.

\section{PEMBAHASAN}

\section{Perpustakaan sebagai Penopang Pendidikan Tinggi}

Memasuki Era revolusi industri 4.0, Internet menjadi suatu keharusan yang wajib digunakan dalam aktivitas sehari-hari. Internet telah menjelma seperti barang wajib. Akibatnya terjadi perubahan perilaku masyarakat yang semakin terbiasa dengan penggunaan teknologi informasi, menuntut layanan yang serba cepat dan lebih bersikap aktif

Inovasi terus berkembang memasuki tahun 2019 ini mulai dari peran robot di bidang industri, Artificial Intelligence (kecerdasan buatan), Drone Operation Centre, Self-Powered Data Centre, hingga rencana pengembangan Virtual Workers. Pada Revolusi Industri 4.0 terdapat banyak inovasi baru, diantaranya Internet of Things (IoT), Big Data, percetakan 3D, kecerdasan buatan (artificial intelligence/AI), kendaraan tanpa pengemudi, rekayasa genetika, robot dan mesin pintar. Salah satu hal terbesar dalam Revolusi Industri 4.0 adalah penemuan Internet of Things. Sebagai sebuah revolusi, maka revolusi

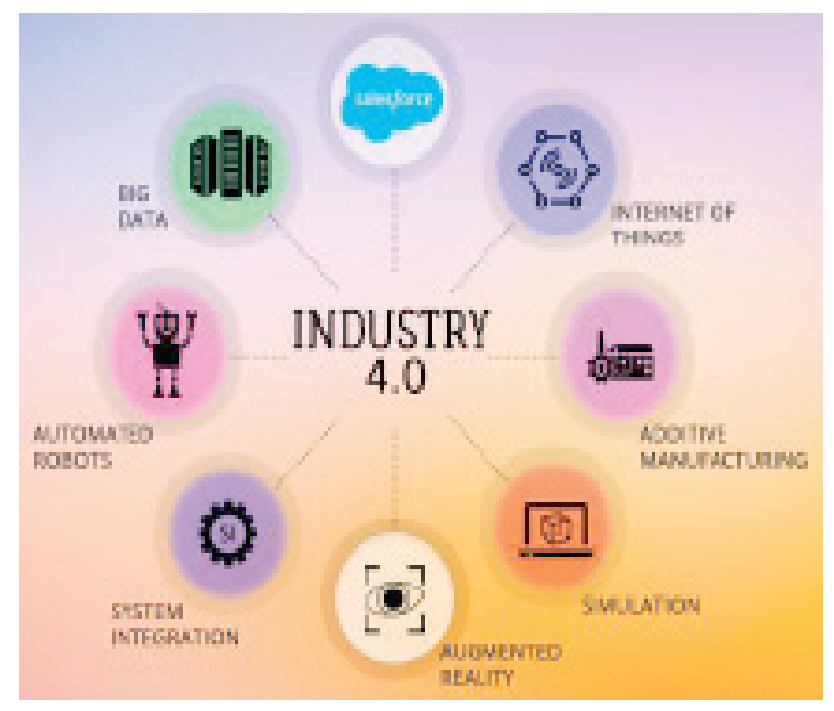

Gambar 1. Wajah Revolusi Industri 4.0 industri 4.0 sangat berdampak kepada ekosistem dunia dan tata cara kehidupan manusia. Jadi, dalam industri 4.0 penggunaan komputer dan robot merupakan hal yang paling mendasar. Hal ini bisa dilihat dalam gambar 1 .

Perpustakaan memainkan bagian penting dalam ekosistem pendidikan sebagai sumber pengetahuan dan penopang kegiatan belajar mengajar, baik untuk para pendidik, maupun peneliti. Tanpa sarana perpustakaan yang baik, proses aktivitas pendidikan tinggi akan berjalan lambat karena perpustakaan menopang berbagai kebutuhan yang melibatkan ilmu pengetahuan, termasuk untuk repository wadah bagi koleksi publikasi akademisi. dua puluh tahun terakhir, perpustakaan akademik telah menghasilkan semakin banyak informasi tentang operasi mereka (Kassim, 2017).

Perpustakaan akademik tidak hanya menyediakan akses ke konten di dalam gedung mereka, tetapi juga peralatan dan teknologi yang dapat dilihat dan digunakan siswa dalam kegiatan pendidikan mereka. Sementara itu, beberapa anggota pustakawan juga ahli dalam bidang penelitian, yang mana bisa bekerjasama dengan para pengajar dalam mendesain kurikulum mata kuliah. Kerjasama tersebut dibutuhkan karena dibutuhkan pemikiran kritis dan literasi informasi dalam pengembangan kurikulum, dibutuhkan pula akses sumber daya literatur dan konten gratis, yang mana sangat berguna bagi mahasiswa kurang mampu (D'Elia and Walsh, 1983).

Perpustakaan kampus telah banyak berubah diabad 21 untuk fokus pada pengembangan pengumpulan jumlah koleksi dan sumber daya digital. Perpustakaan kampus saat ini biasanya menyediakan akses ke koleksi online berbasis langganan, termasuk basis data penelitian dan koleksi e-book, di samping buku fisik dan jurnal. Biasanya, pihak universitas akan berlangganan koleksi jurnal kredibel seperti elsevier, Taylor \& Francis, Springer, dan penerbit lain, yang hanya bisa diakses melalui komputer perpustakaan. Pihak perpustakaan juga menyediakan versi cetak dari jurnal jurnal langganan universitas tersebut yang bisa dipinjam oleh para mahasiswa dan staf pengajar. Beberapa perpustakaan akademik meminjamkan teknologi seperti kamera video, iPad, dan kalkulator. Untuk beradaptasi dengan revolusi industri ke 4.0, banyak perpustakaan kampus telah direnovasi menjadi lembaga pembelajaran masal. Fasilitas tersebut sering menjadi tempat bimbingan belajar dan praktik penulisan ilmiah para akademisi (Black and Muddiman, 2017).

Untuk menyesuaikan diri dengan perkembangan zaman, perpustakaan juga dituntut untuk memperbarui 
koleksi sesuai dengan ilmu pengetahuan terbaru. Selain itu, perpustakaan wajib menyediakan fasilitas perangkat digital yang dilengkapi dengan teknologi terbaru karena piranti lunak selalu memperbarui versi mereka, termasuk piranti lunak untuk kegiatan penelitian. Butuh biaya yang sangat besar untuk terus memperbarui perangkat digital yang dimiliki, dan kerjasama dengan pihak asing sebagai sponsor merupakan langkah alternatif yang bisa diambil untuk mengatasi masalah sumber daya yang terbatas ini (Anna et al., 2019).

Kedatangan revolusi industri 4.0 telah merubah wajah perpustakaan perguruan tinggi. Salah satu contohnya adalah perpustakaan digital. Dahulu orang yang ingin membaca buku harus datang ke perpustakaan, namun saat ini perpustakaan universitas sudah menyediakan layanan online untuk pemustakanya berupa e-books, e-journals, dan sebagai berikut untuk dibaca atau diunduh. Untuk orang awam pun sudah banyak tersedia dan tersebar di internet dimana kita tinggal mencari informasi secara baik dan mengaksesnya.

Oleh karena itu muncul banyak harapan dengan adanya revolusi industri 4.0 ini perpustakaan yang menjadi tameng utama atau fondasi dasar perpustakaan dapat berkembang menjadi lebih baik lagi mengikuti perkembangan perpustakaan di negara maju. Sehingga bisa dipastikan bahwa apabila perpustakaan bisa berkembang, maka minat belajar yang yang dimiliki rakyat Indonesia pun akan berkembang menjadi lebih baik pula. Era revolusi industri 4.0, perpustakaan dan pustakawan dituntut berperan proaktif dan dinamis.

\section{KESIMPULAN}

Revolusi industri ke 4.0 memaksa masyarakat untuk beradaptasi dengan kemajuan zaman secara cepat dengan membekali diri mereka dengan ilmu pengetahuan dan informasi. Perpustakaan sebagai instansi penyedia informasi dan koleksi literasi mempunyai tanggung jawab untuk menyesuaikan diri dengan perkembangan zaman. Perpustakaaan kampus/pendidikan tinggi menggunakan teknologi digital terbaru untuk menjawab kebutuhan para akademisi. Berbeda dengan era sebelumnya, kini koleksi perpustakaan juga disediakan dalam format digital agar bisa diakses dimanapun. Untuk itu sebuah perpustakaan tidak boleh berhenti berinovasi. Kedepan bisa menjadi tempat untuk menemukan informasi yang berharga bagi pemustakanya dan bisa memberikan nilai tambah bagi orang-orang disekitarnya.

\section{DAFTAR PUSTAKA}

Alvermann, D.E., Sanders, R.K., 2019. Adolescent literacy in a digital world. Int. Encycl. media Lit. 1-6

Anna, N.E.V., Mannan, E.F., Srirahayu, D.P., 2019. Evaluation of the Role of Society-Based Library in Empowering Surabaya City People. Public Libr. Q. $1-13$.

Bauer, A.T., Ahooei, E.M., 2018. Rearticulating Internet Literacy. J. Cybersp. Stud. 2, 29-53

Black, A., Muddiman, D., 2017. Understanding community librarianship: the public library in post-modern Britain. Routledge.

D’Elia, G., Walsh, S., 1983. User satisfaction with library service: a measure of public library

performance? Libr. Q. 53, 109-133.

Kalarensi Naibaho. 2017. Blended Skill Bagi Pustakawan Akademik Dalam Menghadapi Era Revolusi Industry. Jurnal Pustakawan Indonesia Vol. 17 No. 12017.

Kassim, N.A., 2017. Evaluating users' satisfaction on academic library performance. Malaysian J. Libr. Inf. Sci. 14, 101-115.

Klaus Schwab. 2016. The Fourth Industrial Revolution. World Economic Forum.

Nora Junita Azmar. 2018. Masa Depan Perpustakaan Seiring Perkembangan Revolusi Industri 4.0: Mengevaluasi Peranan Pustakawan. Jurnal Iqra' Volume 10 No.01, 2018.

Perpustakaan Nasional RI. 2014. Peraturan Pemerintah Republik Indonesia Nomor 24 Tahun 2014 tentang Pelaksanaan Undang-Undang Nomor 43 Tahun 2007 Teantang perpustakaan. Jakarta: Perpusnas, 2014.

Shank John, The Blended Librarian: A Blueprint for Redefining the Teaching and Learning Role of Academic Librarians. College \& Research Libraries News 65, no. 7 (July/August 2004): 374.

Sugiyono. 2010. Metode Penelitian Bisnis: Pendekatan Kuantitatif, Kualitatif dan $R \& D$. Bandung: Alfabeta. Anggota IKAPI.

Suwono, H., 2017. School literary movement in Indonesia: Challenges for scientific literacy, in: International Conference on Education (ICE2) 2018: Education and Innovation in Science in the Digital Era. pp. 309-317 